\title{
A Proposed Design for a Smart Shock Absorber Using an Electro-Rheological Fluid
}

Dr. Ahmed Nooh, PhD1, Dr. Carlos Monroy, PhD2, Michael Anwr Alphonse Anees, BS1, and Wafik Girgis, BS1 1The American University in Cairo,Egypt, alaanooh@hotmail.com,m_alphonse@aucegypt.edu. wafikgirgis@aucegypt.edu 2Universidad Polytechnica de Madrid, Spain, crmonroy@etsii.upm.es,

This paper proposes a design for a smart down-hole shock absorber that can be used to optimize the vibrations that occur while drilling oil and gas wells. The tool reads the magnitude and frequency of vibrations resulting from the drilling process. It then compares those parameters to the recommended ranges that the drilling bit requires to achieve the highest rate of penetration in a given formation with the slightest damage occurring to drilling equipment. Accordingly, the smart shock absorber changes its properties to damp the vibrations and make them fall into the recommended range of vibrations. The paper starts with a quick introduction about why shock absorbers are used in drilling for oil and gas. Next, we discuss different vibration problems that occur while drilling. Then we present a brief review about smart fluids. Then we present the proposed design of the smart shock absorber. Finally, we discuss optimum placement of a shock absorber in the BHA.

Keywords—smart fluid, axial vibrations, drill-string, ERF, MRF

Digital Object Identifier

(DOI):http://dx.doi.org/10.18687/LACCEI2016.1.1.211

ISBN: 978-0-9822896-9-3

ISSN: $2414-6390$

$14^{\text {th }}$ LACCEI International Multi-Conference for Engineering, Education, and Technology: "Engineering Innovations for Global Sustainability", 20-22 July 2016, San José, Costa Rica. 


\title{
A Proposed Design for a Smart Shock Absorber Using an Electro-Rheological Fluid
}

\author{
Dr. Ahmed Nooh, $\mathrm{PhD}^{1}$, Dr. Carlos Monroy, $\mathrm{PhD}^{2}$, Michael Anwr Alphonse Anees, $\mathrm{BS}^{1}$, and Wafik Girgis, $\mathrm{BS}^{1}$ \\ IThe American University in Cairo,Egypt,alaanooh@hotmail.com,m_alphonse@aucegypt.edu.wafikgirgis@aucegypt.edu \\ ${ }^{2}$ Universidad Polytechnica de Madrid, Spain, crmonroy@etsii.upm.es,
}

\begin{abstract}
This paper proposes a design for a smart down-hole shock absorber that can be used to optimize the vibrations that occur while drilling oil and gas wells. The tool reads the magnitude and frequency of vibrations resulting from the drilling process. It then compares those parameters to the recommended ranges that the drilling bit requires to achieve the highest rate of penetration in a given formation with the slightest damage occurring to drilling equipment. Accordingly, the smart shock absorber changes its properties to damp the vibrations and make them fall into the recommended range of vibrations. The paper starts with a quick introduction about why shock absorbers are used in drilling for oil and gas. Next, we discuss different vibration problems that occur while drilling. Then we present a brief review about smart fluids. Then we present the proposed design of the smart shock absorber. Finally, we discuss optimum placement of a shock absorber in the BHA.
\end{abstract}

Keywords—smart fluid, axial vibrations, drill-string, ERF, MRF

\section{INTRODUCTION}

\section{A. Why are shock absorbers used in the oil field}

Owners of oil and gas wells and drilling operators are mostly concerned about reducing the cost of drilling petroleum wells. One approach to reducing the drilling costs is to develop an optimum drilling programs. A key element of an optimum program involves the use of appropriate drilling tools such as shock absorbers.

A shock absorber is a tool which is run in the lower portion of the drill string to reduce shock loading and absorb vibrations produced during the drilling process. It reduces the harmonic frequencies generated in the drill string while drilling. These vibrations, if not minimized by the shock absorber, can result in damage to the drill string, drill bit, and surface drilling equipment. A properly designed shock absorber not only minimizes drill-string vibration, but also helps keep the bit on the bottom of the hole, which increases drilling speed or as referred to in the petroleum engineering discipline, the Rate Of Penetration (ROP).

It is worth mentioning that although the popularity of shock absorbers has grown, a few problems are being reported. The flexibility of the shock absorber (or lack of rigidity), and the high chance of fatigue failure in its components are cited by few in the industry as creating a higher risk of hole-control problems, negating the potential benefits of the tool [1] [2].

\section{B. Drilling vibrations types and problems}

Vibrations occur mainly as three main types as shown in figure 1: axial vibration, torsional vibration, and lateral vibration [3].

Digital Object Identifier (DOI): http://dx.doi.org/10.18687/LACCEI2016.1.1.211 ISBN: 978-0-9822896-9-3

ISSN: $2414-6390$

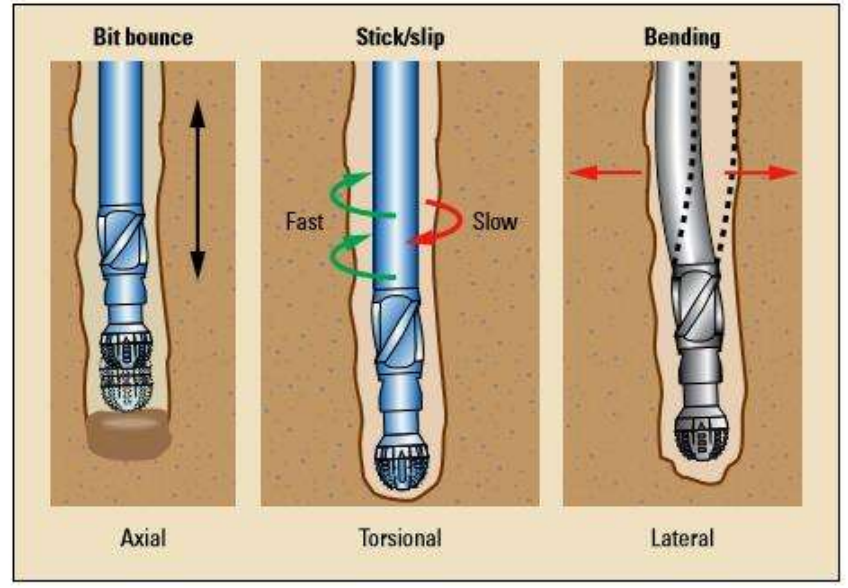

Figure 1. Vibration Types and effect on the drill-string and drill bit. Source:

[3]

1) Axial vibrations: This type of vibrations is the main vibration responsible for the occurrence of Bit Bounce ${ }^{1}$ while drilling, which by turn causes wear and damage of the drillstring, and the drill bit.

2) Torsional vibration: This type of vibrations is responsible for the irregular downhole rotation that occurs in the drilling operation.

3) Lateral vibration: This type of vibration is responsible for the bending that occurs in the drilling string during the drilling operation.

In this paper, we propose a new design for a smart shock absorber that uses smart fluids to control the axial vibration severity and frequency according to the bit requirements. The goal is not to damp the system too much, which would reduce ROP, or too little, which would cause damage to the equipment as discussed above.

This type of smart shock absorbers has been introduced to other industries using smart fluids in hydraulic shock absorbers. Thus, we adapt the concept into the oil and gas industry and propose a design for a shock absorber that can be installed in the drill-string.

\section{SMART FLUIDS, THEIR APPLICATIONS IN VIBRATION}

DAMPING, AND SELECTION OF THE PROPER FLUID FOR THE SMART SHOCK ABSORBER

\section{A. How smart fluids are used nowadays?}

\footnotetext{
${ }^{1}$ Bit Bounce is the bouncing of the drilling bit on and off the bottom of the whole being drilled.
} 
Over the past few years, smart fluids and particularly the Electro-Rheological Fluid (ERF) and Magneto-Rheological Fluid (MRF), have been used to damp oscillations in systems where critical controllable damping was needed. They have been tested in car dampers, washing machines, robot- arm oscillation damping, computer hard drives...etc [4]. The smart fluids can even exert surplus force, that is- not only damp external forces, but create forces when excited as well. In bioengineering applications, smart fluids are used to move artificial support components such as legs, arms, and even fingers [5].

\section{B. Electro-rheological fluid properties}

ERF are composed of a non- conducting liquid with solid particles that are electrically polarizable and dispersed in the liquid [6]. When an ERF is excited by an electrical current, its viscosity changes and accordingly the damping force the ERF can exert on the system changes. Thus, the force is governed by the following equation where $\mathrm{dx} / \mathrm{dt}$ is the speed at which a vibrating system oscillates and $\mathrm{E}$ is the electric field intensity applied to the system:

$F_{d}=Y\left(\frac{d x}{d t}, E\right)$

There are a few types of ER fluid. We mention two of them in the following section:

1) Colloidal electro-rheological fluid of the particle dispersion type: The colloidal fluid types possess Bingham fluid characteristics [7]. Hence, it can withstand high shear stress, and act like a solid without straining as shown in fig.2(a) until stress exceeds a certain point in which case, the fluid acts like a viscous liquid and shear rate increases. Of course, the stress force at which strain starts occurring depends on the velocity at which the fluid is moving. (in our case, this would be a function of the vibration frequency occurring downhole).

\section{2) Homogenous electro-rheological fluid}

The homogenous ER fluid is composed of low molecular crystals or polymer crystals that has Newtonian characteristics [7]. As soon as shear stress is applied, shear strain occurs, and as soon as shear stress is removed, shear strain disappears. The relationship between shear stress and shear strain is fixed and is linear as seen in fig.2(b).

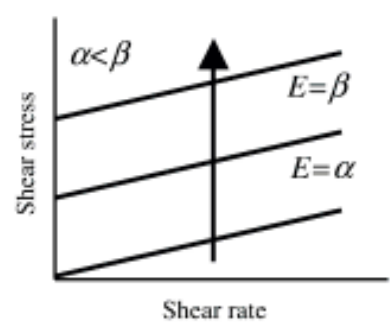

(a)

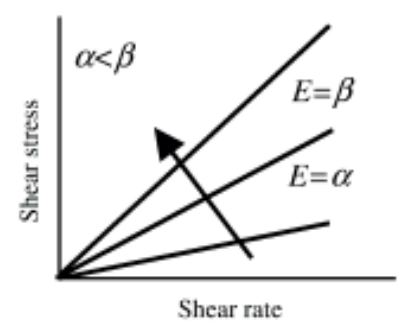

(b)
Figure 2. Characteristics of the two types of ER fluid: (a) particle -type ER fluid, (b) Homogenous ER fluid. Source: [7]

\section{Magnetic-rheological fluid properties}

Magnetic-Rheological Fluid (MRF) can be excited to produce force rather than produce damping effects only. It is excited by an electromagnetic field of few volts and kilo amperes [8], although newer papers report less power requirement (of few amperes) [9]. It is worth mentioning that MRFs are ferromagnetic in nature, which allows some residual particles to oscillate at energies that are lower than the activation energy of the damping system and consequently bypass the damper into the system, causing loss of the MRF matter [5].

D. Comparing and choosing a smart fluid to be used in the smart shock absorber

1) Power requirement: the power requirements for ERF is in the range of kilovolts and milliamps, while the power requirements to excite an MRF is in the range of kiloamps, and millivolts, thus the power requirements for both is within the same range.

2) sub-fluid particles bypassing the system: as mentioned earlier, the fine particles in the MRF bypass the damper into stagnant positions around the piston or on the walls of the shock absorber. When those fine particles collect on the walls of the container, they exert extra force on the walls, and subsequently affect the wall integrity by time. ERF does not cause such troubles. Thus, according to this criterion, we preferred ERF to be used in the shock absorber.

3) the direction of force created when either of the smart fluid is excited: when the MRF is excited, it creates a force that not only cancels opposite forces (dampening force), but it can further create surplus force within the system. The ERF only creates force when excited to counteract external forces (dampening force) [5]. The difference here may not affect the choosing process much.

4) Excitation method: MRFs are excited using electromagnetic field, which might have unstudied and unneeded effects on the magnetic surveying tools used in the oil industry. The ERF on the other hand, is excited using an electric field, which would not affect the magnetic surveying tools as much. Thus, we preferred the ERF according to this criterion. Nonetheless, the effects of having an electric field downhole needs further investigation. See table 1 below.

$14^{\text {th }}$ LACCEI International Multi-Conference for Engineering, Education, and Technology: "Engineering Innovations for 
Table 1. Choosing between MRF and ERF- liquid problems and why ERF is chosen

\begin{tabular}{|c|c|c|c|c|}
\hline & Problem & MRF & ERF & $\begin{array}{l}\text { Preferred } \\
\text { liquid }\end{array}$ \\
\hline 1 & $\begin{array}{l}\text { Power } \\
\text { requirements }\end{array}$ & $\begin{array}{l}\text { kAmps, } \\
\text { mVolts }\end{array}$ & $\begin{array}{l}\text { kVolts, } \\
\text { mAmps }\end{array}$ & $\begin{array}{l}\text { Equal power } \\
\text { requirement }\end{array}$ \\
\hline 2 & $\begin{array}{l}\text { Mini particles } \\
\text { bypassing the } \\
\text { damper in the } \\
\text { system }\end{array}$ & yes & no & ERF \\
\hline 3 & Force created & $\begin{array}{l}\text { Surplus force } \\
\text { exerted by } \\
\text { fluid }\end{array}$ & $\begin{array}{l}\text { Only damping } \\
\text { force exerted } \\
\text { by fluid }\end{array}$ & \\
\hline 4 & $\begin{array}{l}\text { Excitation } \\
\text { method }\end{array}$ & $\begin{array}{l}\text { Electro- } \\
\text { magnetic field } \\
\text { may affect } \\
\text { magnetic } \\
\text { surveying } \\
\text { systems) }\end{array}$ & Electric field & ERF \\
\hline
\end{tabular}

Table 1 shows a summarized comparison of certain properties of MRF vs. ERF. ERF (whether colloidal or homogenous type) is chosen due to problems 2 and 4 that would occur if an MRF is chosen instead.

\section{GOVERNING EQUATIONS OF AXIAL VIBRATION IN A DAMPER}

Assume there is a container that contains a viscous fluid and that there is a piston moving against the viscous fluid. In addition, assume that the piston is also moving against a spring and another mechanical damper placed left to the string as shown in figure 3. Next, assume there is a weight, mg attached at the bottom of the containers. Finally, assume that the vibrations are caused at the bottom of the system and they cause the piston to move against the viscous fluid, the spring, and the damper as explained earlier.

The forces exerted on the system are broken down as follows [10]:

1) There is a force generated by the spring and can be quantified as $\mathrm{K}$ (spring constant) times the spring elongation. The spring elongation is expressed as sst $+x$, where \&st is the "equilibrium position" induced by the weight of the shock absorber components, and the

2 POOH: Pull Out Of Hole- a term used in the oil and gas industry to mean pulling the drill-string (composed of many drill pipes and other drilling tools) out of the whole and disassembling it) additional elongation, $\mathrm{x}$ is induced by further external forces on the system, such as axial drilling vibrations, and tensile load due to $\mathrm{POOH}^{2}$ or increasing weight on bit ${ }^{3}$; we will refer to those external forces as $\mathrm{F}_{\mathrm{e}}$.

2) There is a force generated by the damper element (damper force), $c \frac{d r}{d t}$, where $r=x+s_{s t}+\mathrm{l}$ and $\mathrm{C}$ is the damping coefficient;

3) The weight of the shock absorber component is $\mathrm{mg}$;

4) Another term that needs to be accounted for is the inertia force $=m \frac{d^{2} r}{d t^{2}}$. However, in this case, the inertia force is equal to zero, assuming that there is no rotation in any of the damper components.

Now the forces exerted on the system so far are mentioned as follows:

$k\left(x+\aleph_{s t}\right)+c \frac{d r}{d t}+m \frac{d^{2} r}{d t^{2}}=m g+f_{e}$.

Since inertia force is equal to zero,

$k\left(x+s_{s t}\right)+c \frac{d r}{d t}+0=m g+f_{e}$.

Further, to add the effect of the viscous fluid to the governing equation, [10] modelled the damping force, $\mathrm{F}_{\mathrm{f}}$ due to a piston pressing against a viscous fluid (the ERF in this case) with the following equation:

$F_{F}=-k_{o} m \frac{d 2 x}{d t^{2}}-c_{f} \frac{d x}{d t}$,

where $c_{f}$ is the fluid damping coefficient which depends on the fluid viscosity.

Combining 3 and 4, the final governing equation of the system is as follows:

$k\left(x+\varsigma_{s t}\right)+c \frac{d r}{d t}+k_{o} m \frac{d 2 x}{d t^{2}}+c_{f} \frac{d x}{d t}=m g+f_{e}$.

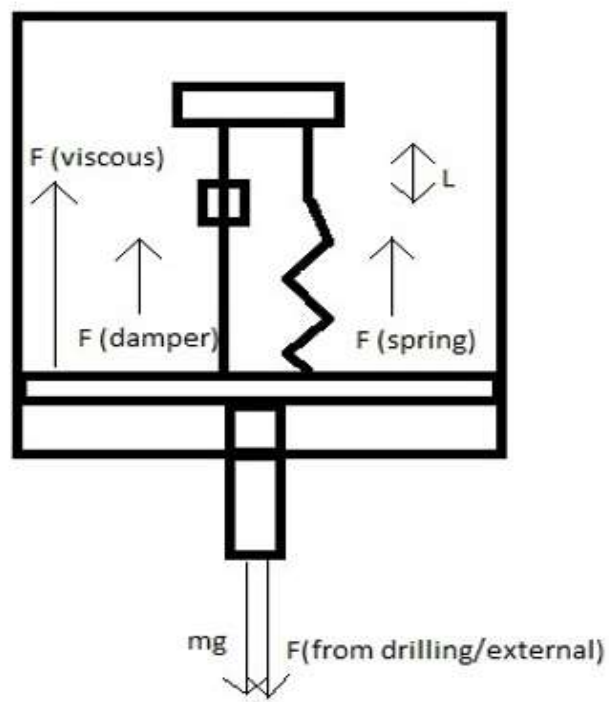

Figure 3. Force effect on a hydraulic shock absorber

${ }^{3}$ Weight on bit (WOB): a term used in the oil and gas industry to measure the weight exerted by the drill-string on the drill bit. WOB is necessary to achieve high drilling speed or ROP. 
It is important to note that had the system been completely damped, $\frac{d x}{x t}$ and $\frac{d r}{d t}$, would have equaled zero. Drilling, however, as noted before, requires vibration intensity at a specific range to help the bit penetrate both fast and safe. The objective is to control the vibrations to fall in the optimized range (determined by bit manufacturers, soil conditions, and drilling engineers), by changing the viscosity of the viscous damping liquid. In this case the viscous damping liquid is ERF which viscosity we can control.

Next we introduce the proposed design of the shock absorber using ERF.

\section{SHOCK ABSORBER DESIGN}

\section{A. Working principle}

The absorber is similar to other viscous-damping type absorbers with few modifications to suit the drilling process and maintain the circulation process ${ }^{4}$. It is composed of an outer barrel that encloses the inner components and the inner barrel that allows mud circulation through it. The drill string is attached to the outer barrel. The drill bit is attached to the inner barrel. When axial vibrations occur in the absence of a shock absorber, the drill bit would vibrate against the drill string. However, if the shock absorber is installed in between them, the bit transfers the axial vibrations to the inner barrel which vibrates against the inner components that separate the inner barrel from the outer barrel. The inner components that absorb the shock are a spring, a mechanical damper, and the ERF trapped between the pistons. See figure 4 .

\section{$B$. Inner components}

The inner components between the inner and the outer barrel are: 1. Seals between the outer wall of the inner barrel and the inner wall of the outer barrel to contain the fluid; 2. a piston attached to the inner barrel; 3 . a piston attached to the outer barrel; 4. a spring installed vertically between the two pistons as shown; 5. a mechanical damper installed vertically between the two pistons as shown; 6 . a pressure barrel that includes the electric chipset and the electronic controller; 7. Two fixed electric electrodes across the inner wall of the outer barrel; 8. an accelerometer that is used to read the vibrations and send the reading feed to the electric chipset inside the pressure barrel; 9. a turbine that is installed to generate the electrical power needed to activate the smart fluid. The thread that will be installed towards the drill bit is a box-regular thread type, attached to the inner barrel. The thread on the other end is a regular pin thread type, attached to the outer barrel. The outer diameter of the damper is always less than the outer diameter of

\footnotetext{
${ }^{4}$ Circulation is a term used in the oil and gas industry where drilling fluids are circulated through the wellbore and up to the surface. Circulation is necessary while drilling to clean rock cuts and lubricate and cool the drill bit.

${ }^{5}$ Reamers are equipment attached to the drill string to maintain the hole diameter constant.
}

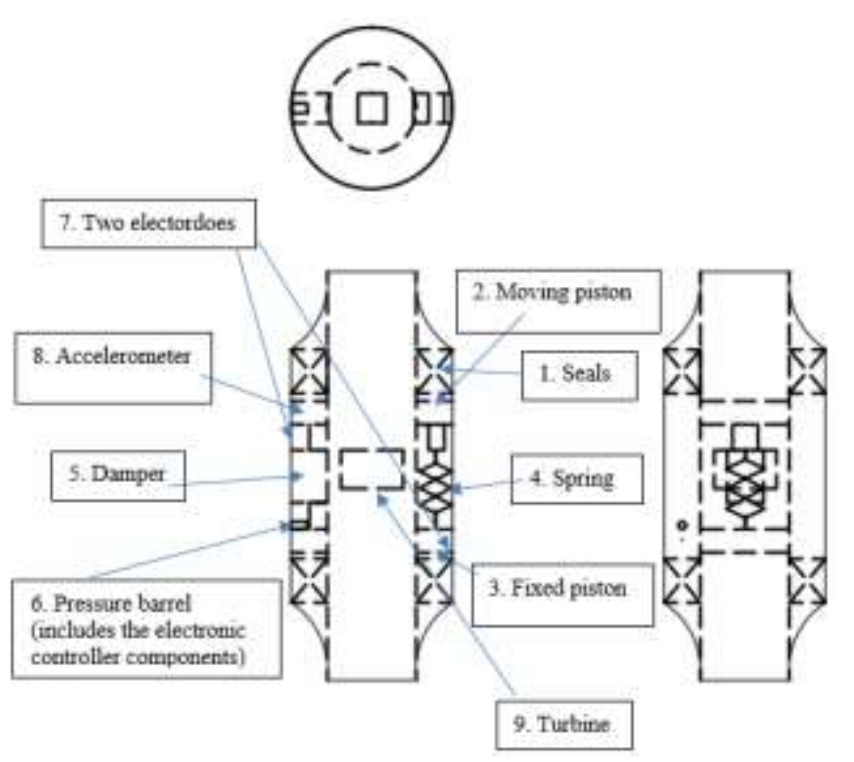

Figure 4. Shock absorber inner design

the bit, stabilizers ${ }^{5}$, or reamers ${ }^{6}$ to make sure it would not cause mechanical sticking?

\section{Controlling mechanism}

According to equation 5, by changing the viscosity of the ERF trapped between the two pistons, the speed of axial vibration, $\frac{d x}{d t}$, changes accordingly.

We can control the ERF viscosity by changing the electric field in the shock absorber. A variable structure control with sliding-mode control (SMC), or a feedback controller can be used to calculate the induced system vibrations (using accelerometers), and accordingly, change the viscosity of the viscous damping liquid by changing the electrical field. This calculated change will move the vibration frequency into the optimized range. The SMC and the feedback controller are extensively discussed in details in literature and can easily be utilized to achieve system response to about 0.2 seconds, without overshooting (increasing viscosity more than needed) or lagging. The controller system and governing equations can be found at (Viscous Control of Homogeneous ER Fluid Using a Variable Structure Control by Taro Nakamura, and Norihiko Saga [7]) and easily be embedded into a microchip in the system. Such controllers, and the rest of the electronic components, however, are beyond the scope of this paper.

${ }^{6}$ Stabilizers are equipment attached to the drill string to maintain the well trajectory without much deviation from the planed trajectory. They stabilize the bit direction.

${ }^{7}$ Mechanical sticking is a type of sticking where the drill string is stuck against the drilled formation (soil).

$14^{\text {th }}$ LACCEI International Multi-Conference for Engineering, Education, and Technology: "Engineering Innovations for 


\section{OPTIMUM PLACEMENT OF A SHOCK ABSORBER IN THE DRILLING STRING}

How much we can benefit from a shock absorber during drilling a well depends on the placement of the tool in the drill string. The proper placement of the tool depends upon the type of Bottom Hole Assembly (BHA) ${ }^{8}$ to be used, the types of formations to be drilled, and their tendency to cause deviation while drilling.

In general, it is recommended that whenever possible the shock absorber be placed directly above the bit. This position in the drill string will provide the maximum benefit from the tool [1]. However, there are cases where certain drilling tools need to be installed above the drill bit. The most important case is building an angle (also called building inclination) in a directional well as in fig 5 below. To build an angle, a stabilizer needs to be installed right above the bit $[11,12]$, thus the shock absorber may need to be shifted upwards, sacrificing a little portion of the damping efficiency.

When formations which present minimum deviation tendencies are drilled or when there is no need to drill a directional well - negating the requirement for reamers or stabilizers to be used (slick string) - the shock absorber should be placed directly above the bit.

Also, when the BHA is configured to drop the angle after building enough inclination in a directional well, a BHA assembly that is called a pendulum assembly is used where the stabilizers are only installed distant from the bit [11, 12],

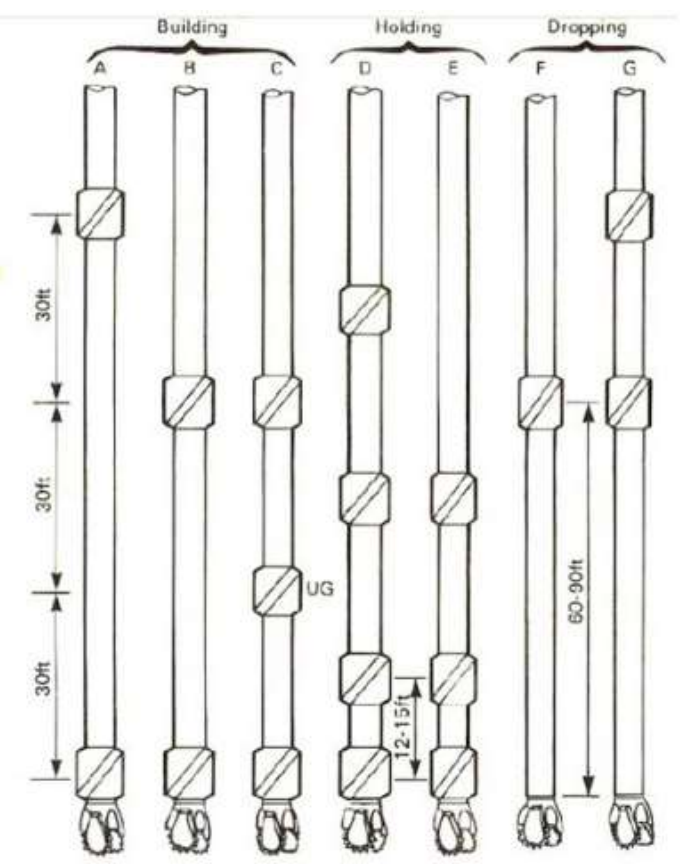

Figure 5. Building, hold and drop assemblies. Source: directionaldrilling.blogspot.fr and [11].

${ }^{8}$ BHA or bottom hole assembly is the lowest part of the drill string. It may be composed of several stabilizers, reamers, shock absorbers, and other drilling tools.
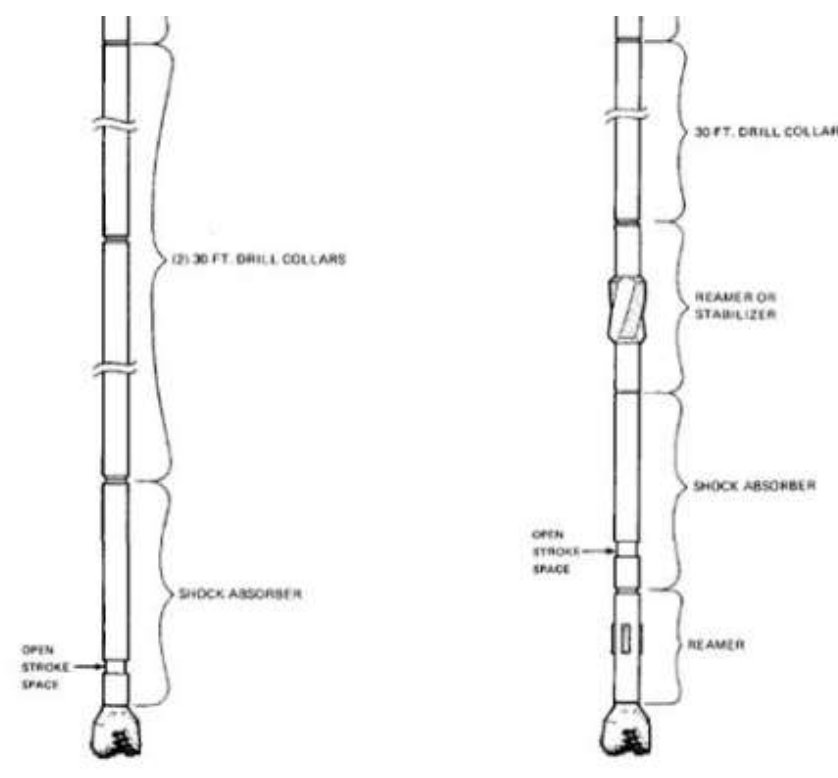

Figure 6. Shock absorber installed directly above the bit (left), and above a reamer (right). Source: [1]

allowing for enough space to install the shock absorber as close as possible from the bit.

There are other problems that necessitate using a tool right above the bit instead of using a shock absorber. For instance, a reamer may be required right above the bit to maintain the wellbore diameter constant (maintain gauge). In such case, the drilling engineer will be forced to place the shock absorber(s) above the reamer as in figure 6 below. In general, it is better to place the shock absorber right above the bit unless it is necessary to shift it upwards and use another tool instead. This condition should also apply to using the smart shock absorber.

\section{CONCLUSION}

Shock absorbers have been found beneficial for drilling economics. They reduce drilling time by increasing bitformation contact time and elongating the bit lifetime. Vibrations cause damage to the drill-bit and drill-string. Axial vibration is a type of vibration where the drill string bounces off the formation while drilling. We proposed a smart shock absorber that measures the vibration frequency and intensity, compares it to the recommended range of vibration required to achieve the highest rate of penetration. If the measured vibration parameters are found to be higher than the recommended range, an electronic controller produces an electric field that excites an electrorheological fluid within the shock absorber. Based on the intensity of the electric field and time of exposure, the viscosity of the electrorheological fluid increases. The fluid then acts as a hydraulic damper for the axial 
vibrations. This kind of automated control will optimize the well drilling parameters based on the needed degree of vibrations. Finally, we discussed the optimum placement of a shock absorber in the drill-string; and cases where the optimum placement of a shock absorber will be compromised to allow more critical tools to be installed where the shock absorber should be to make the drilling process more effective.

\section{ACKNOWLEDGEMENT}

We would like thank the Logging While Drilling engineers at Baker Hughes Egypt and the Measurement While Drilling engineers at Halliburton Egypt who have shared their insights and expectations regarding drilling vibrations and how they negatively affect their measurement tools.

\section{REFERENCES}

[1] S. Warford and P. Craig, "Shock Absorbers-Are They Necessary?," New Orleans, Louisiana, 1983.

[2] A. Ghasemloonia, D. G. Rideout, S. D. Butt and A. Hajnayeb, "Elastodynamic and finite element vibration analysis of a drillstring with a downhole vibration generator tool and a shock sub," Journal of Mechanical Engineering Science, vol. 229, no. 8, pp. 1361-1384, 2015.

[3] Schlumberger, "Drillstring Vibrations and Vibrations Modelling," [Online]. Available: http://www.slb.com/ /media/Files/drilling/brochures/drilling _opt/drillstring_vib_br.pdf. [Accessed 14 February 2014].

[4] S.-B. Choi, N. M. Wereley, W. Li, M. Yu and J.-H. Koo, "Applications of Controllable Smart Fluids to Mechanical Systems," Advances in Mechanical Engineering, vol. 6, 2014.

[5] J. Ouellette, "Smart Fluids Move into the Marketplace," Industrial Physicist, vol. 9, no. 6, p. 14, January 2004.

[6] R. H. W. Hoppe, G. Mazurkevitch, U. Rettig and O. V. Stryk, "Modeling, Simulation, and Control of Electrorheological Fluid Devices," HIGH PERFORMANCE SCIENTIFIC AND ENGINEERING COMPUTING, vol. 8, pp. 157-166, 2000.

[7] T. Taro Nakamura and N. Saga, "Viscous Control of Homogeneous ER Fluid Using a Variable Structure Control," IEEE/ASME Transactions on Mechatronics, vol. 10, no. 2, pp. 154 - 160, 2005.

[8] D. E. Simon and M. Ahmadian, "Experimental Evaluation of Semiactive Magnetorheological Primary Suspensions for Heavy Truck Applications," Virginia Tech, Blacksburg, unpublished.

[9] D. Baranwal and D. T. Deshmukh, "MR-Fluid Technology and Its Application- A Review," International Journal of Emerging Technology and Advanced Engineering, vol. 2, no. 12, 2012.

[10] B. Balachandran and E. B. Magrab, Vibrations, THOMSONBROOKS/COLE, 2005.
[11] J. A. T. Bourgoyne, K. K. Millheim, M. E. Chenevert and J. F. S. Young, "Directional Drilling," in Applied Drilling Engineering, Society of Petroleum Engineers, 1986.

[12] K. Mantle, "The Art of Controlling Wellbore Trajectory," 2014. [Online]. Available:

http://www.slb.com/resources/oilfield_review/ /media/Files/r esources/oilfield_review/ors13/win13/defining_dir_drill.ashx. 
$14^{\text {th }}$ LACCEI International Multi-Conference for Engineering, Education, and Technology: "Engineering Innovations for Global Sustainability”, 20-22 July 2016, San José, Costa Rica. 